Saudi Journal of Medical and Pharmaceutical Sciences

Abbreviated Key Title: Saudi J Med Pharm Sci

ISSN 2413-4929 (Print) |ISSN 2413-4910 (Online)

Scholars Middle East Publishers, Dubai, United Arab Emirates

Journal homepage: https://saudijournals.com/sjmps

Original Research Article

\title{
"Head and Neck Squamous Cell Carcinoma in Young Adults Patients: A Hospital-Based Study"
}

\author{
H.N. Ashikur Rahaman ${ }^{1 *}$, Shravana Kumar Chinnikatti ${ }^{2}$ \\ ${ }^{1}$ Registrar, Dept. of Clinical Oncology, Enam Medical College \& Hospital, Savar, Dhaka, Bangladesh \\ ${ }^{2}$ Senior Consultant, Dept of Clinical Oncology, Enam medical college Hospital, Savar, Dhaka, Bangladesh
}

DOI: $10.36348 /$ sjmps.2020.v06i02.005

| Received: 18.01.2020 | Accepted: 28.01.2020 | Published: 11.02.2020

*Corresponding author: H.N. Ashikur Rahaman

\section{Abstract}

Background: Head and neck cancers (HNCs) account for 30\% of all cancers in Bangladesh. In Bangladesh, tobacco related cancers are very common because of the widespread use of tobacco. The paucity of any study from this region in young head and neck patients has prompted us to take up this study. Objective: To find out the head and neck squamous cell carcinoma in young adults patients. Methodology: A retrospective study was conducted at Oncology Department, Enam Medical College \& Hospital, and Dhaka, Bangladesh during January 2019 to December 2019. Data regarding tumor site, age, sex, education, habit of tobacco (smokeless and smoke), and betel nut consumption were analyzed using IBM SPSS version 19. P<0.05 was considered as statistically significant. Results: About $75.1 \%$ patients were males. Among patients $\leq 39$ years, $83.7 \%$ were tobacco chewers, $50.5 \%$ were smokers, and $83.7 \%$ betel nut chewers, and among $>39$ years, these proportions were $83.7 \%, 56.2 \%$, and $78.7 \%$, respectively. The most common site among $\leq 39$ years and $>39$ were mouth $(40.8 \%)$ and hypopharynx (36.8\%). Among tobacco and betel nut chewers and smokers, the most common sites were mouth $(40.3 \%, 42.5 \%)$ and hypopharynx $(41.5 \%)$. The site of head and neck squamous cell carcinoma was highly associated with chewing and smoking habit $(\mathrm{P}<0.05)$. Among illiterate patients, proportions of tobacco and betel nut chewers and smokers were $65.3 \%, 61.6 \%$, and $67.9 \%$, respectively. Conclusion: A positive association between tobacco use, male gender, and low education levels were found. The younger generation should be made aware about the adverse health consequences of tobacco use to reduce the preventable risk factors of HNC.

Keywords: Head and neck, squamous cell, tobacco, young.

Copyright @ 2020: This is an open-access article distributed under the terms of the Creative Commons Attribution license which permits unrestricted use, distribution, and reproduction in any medium for non-commercial use (NonCommercial, or CC-BY-NC) provided the original author and source are credited.

\section{INTRODUCTION}

Head and neck cancer (HNC) is one of the most common cancers worldwide with annual incidence more than 550,000 cases, of which around 300,000 deaths occur every year [1]. Bangladesh day by day increase in Head and neck cancer (HNC). Head and neck squamous cell carcinoma (HNSCC) accounts about $90 \%$ of all $\mathrm{HNC}$ which is the sixth leading cancer by incidence worldwide. HNSCC typically develops in sixth to seven decades of life. However, some studies reveal that it has developed in younger age group in different parts of world including India, China, USA, and Europe [2-6]. HNSCC incidence rate in patients below 40 years has reached $0.4 \%-3.6 \%$ [7]. The most common locations where HNSCC arises are the oral cavity, oropharynx, larynx, and hypopharynx [7, 8]. The main risk factors associated with HNSCC are environmental and lifestyle factors such as chewing tobacco, alcohol consumption, and smoking. Recently, epidemiological studies has emerged a strong association with human papillomavirus (HPV) in a subset of HNSCC and in nonsmoking cases [9, 10]. In north eastern parts of India in the states such as Assam, Meghalaya, Mizoram, Tripura, Nagaland, and Manipur, the risk of HNSCC is further associated with the practice of betel quid and areca nut chewing,[11] chewing of smokeless tobacco products [12] and smoking of bidis and cigarettes [13]. However, there is an increase in the number of young HNSCC patients, without history of any typical risk factors. Other risk factors associated with the prevalence of HNSCC are poor dental hygiene, poor diet, immunosuppressant, submucous fibrosis, gastrointestinal reflux, different inherited syndrome, and chronic iron deficiency anemia $[6,14,18]$. Since remarkable differences exist in consumption of alcohol, tobacco, diet, literacy, and social status in the Dhaka City of Bangladesh compared to other parts of the country, we proposed to define in this article the environmental and lifestyle risk factors, age group, tumor location, and literacy among the 
group of HNSCC patients reported in hospital- based cancer registry at Oncology Department, Enam Medical College \& Hospital, Dhaka, Bangladesh, during January 2019-December 2019. Bangladesh shares similar cultural \& social norms as India. Likewise, HNSCC is also the most common cancer in males in Bangladesh, surpassing lung cancer [31]. As extensive use of tobacco (in smoking and smokeless forms) and chewing of areca nut dominate the risks for head and neck cancer across South Asia, less attention has been given to the role of HPV. There are no comprehensive data from Bangladesh. Because of the high burden of this disease in South and South East Asia it is essential to have accurate data on the role of HPV across the region.

\section{Methodology}

The present study is a retrospective study conducted at Oncology Department, Enam Medical College \& Hospital, and Dhaka, Bangladesh on patients who were diagnosed with HNSCC during January 2019 to December 2019. A total of 362 patients ranging from age group 20-40 years who had histologically confirmed cases of squamous cell carcinoma (SCC) of oral cavity, tonsil, oropharynx, nasopharynx, hypopharynx, and larynx were included. Patients with imprecise and incomplete information on clinical and histological data, previously treated cases, and SCC of the other parts of the head and neck were excluded. The present study has been approved by the institutional review board.

\section{Data AnAlysis}

Data regarding tumor site, age, sex, education, habit of tobacco (smokeless and smoke) consumption, and betel nut chewing habit were abstracted from hospital records and analyzed using IBM SPSS version 19.0 (SPSS Inc., Chicago, IL, USA). The variables were analyzed using $\mathrm{Chi}^{-}$square or Fisher's exact test. $\mathrm{P}<0.05$ was considered as statistically significant.

\section{RESULTS}

We reviewed the medical records of 362 HNSCC patients of whom 272 were males and 90 were females (the male to female ratio was $3: 1$ ). The mean and median ages were 38 and 39 (range: 20-40) years, respectively. The patients were divided into two groups, below 39 years or younger $(n=184$ patients) and 39 years above or older ( $\mathrm{n}=178$ patients) based on median age. The mean and median ages in younger patients were 34 and 35 years, and in older patients, they were 41 and 42 years. The male to female ratio in younger and older groups were 2.2:1 and 4.4:1, respectively. The patients' ages differ significantly with their sex [Table 1].

Table-1: Characteristics of patients and patients' age $(\mathrm{N}=362)$

\begin{tabular}{|c|c|c|c|}
\hline \multirow[t]{2}{*}{ Patients' characteristics } & \multicolumn{2}{|c|}{ Patients' age (years) } & \multirow[t]{2}{*}{$\mathbf{P}$} \\
\hline & $\leq 39$ & $>39$ & \\
\hline \multicolumn{4}{|c|}{ Gender } \\
\hline Male & $127(69.0)$ & $145(81.5)$ & \multirow[t]{2}{*}{0.006} \\
\hline Female & $57(31.0)$ & $33(18.5)$ & \\
\hline \multicolumn{4}{|l|}{ Tobacco smokeless } \\
\hline Chewers & $154(83.7)$ & $149(83.7)$ & \multirow[t]{2}{*}{0.997} \\
\hline Nonchewers & $30(16.3)$ & $29(16.3)$ & \\
\hline \multicolumn{4}{|l|}{ Tobacco smoke } \\
\hline Smokers & $93(50.5)$ & $100(56.2)$ & \multirow[t]{2}{*}{0.283} \\
\hline Nonsmokers & $91(49.5)$ & $78(43.8)$ & \\
\hline \multicolumn{4}{|l|}{ Betel nut } \\
\hline Chewers & $154(87.7)$ & $140(78.7)$ & \multirow[t]{2}{*}{0.219} \\
\hline Nonchewers & $30(16.3)$ & $38(21.3)$ & \\
\hline
\end{tabular}

Among the patients in younger age group, 154 $(83.7 \%)$ were tobacco chewers, $93(50.5 \%)$ were smoker, and $154(83.7 \%)$ were betel nut chewer. However, in older age group, $149(83.7 \%)$ were tobacco chewer, $100(56.2 \%)$ were smoker, and 140 (78.7\%) were betel nut chewer. Patients' chewing and smoking habit did not differ significantly with their age. The most prevalent site of HNSCC in younger patients was mouth $(75 / 184=40.8 \%)$ while in older patients, the most common site was hypopharynx $(65 / 178=36.5 \%)$. The site of HNSCC was significantly different with patients' age $(\mathrm{P}=0.012)$. In male, the highest frequencies were observed in two sites, mouth and hypopharynx $(85 / 272=31.3 \%)$ while in female, the highest cases were found in mouth $(40 / 90=44.4 \%)$. There was no significant difference between patients' HNSCC site and sex. Among tobacco chewers, the most common observable location of HNSCC was mouth $(122 / 303=40.3 \%)$ while among smokers, the most common location observed in hypopharynx $(80 / 193=41.5 \%)$. However, mouth was the most frequently observed site of HNSCC among the patients who ever chewed betel nut $(125 / 294=42.5 \%)$. The site of HNSCC was highly associated with chewing and smoking habit $(\mathrm{P}<0.05)$ [Table 2]. 
H.N. Ashikur Rahaman \& Shravana Kumar Chinnikatti; Saudi J Med Pharm Sci, Feb., 2020; 6(2): 173-177

Table-2: Characteristics of patients and tumor site $(\mathrm{N}=362)$

\begin{tabular}{|c|c|c|c|c|c|c|c|c|c|}
\hline \multirow{2}{*}{\multicolumn{2}{|c|}{$\begin{array}{l}\text { Patients'charac } \\
\text { teristics }\end{array}$}} & \multicolumn{7}{|c|}{ Tumor site } & \multirow[t]{2}{*}{$\mathbf{P}$} \\
\hline & & Tongue & Mouth & Tonsil & Oropharynx & Nasopharynx & Hypopharynx & Larynx & \\
\hline \multicolumn{10}{|l|}{ Age (years) } \\
\hline$\leq 39$ & $3(1.6)$ & $27(14.7)$ & $75(40.8)$ & $\begin{array}{l}13 \\
(7.1)\end{array}$ & $9(4.9)$ & $13(7.1)$ & $36(19.6)$ & $8(4.3)$ & 0.012 \\
\hline$>39$ & $2(1.1)$ & $27(15.2)$ & $50(28.1)$ & $\begin{array}{l}10 \\
(5.6)\end{array}$ & $8(4.5)$ & $5(2.8)$ & $65(36.5)$ & $11(6.2)$ & \\
\hline \multicolumn{10}{|l|}{ Gender } \\
\hline Male & $5(1.8)$ & $37(13.6)$ & $85(31.3)$ & $\begin{array}{l}18 \\
(6.6)\end{array}$ & $12(4.4)$ & $14(5.1)$ & $85(31.3)$ & $16(5.9)$ & 0.102 \\
\hline Female & 0 & $17(18.9)$ & $40(44.4)$ & $5(5.6)$ & $5(5.6)$ & $4(4.4)$ & $16(17.8)$ & $3(3.3)$ & \\
\hline \multicolumn{10}{|c|}{ Tobacco smokeless } \\
\hline Chewers & $5(1.7)$ & $43(14.2)$ & $\begin{array}{l}122 \\
(40.3)\end{array}$ & $\begin{array}{l}18 \\
(5.9)\end{array}$ & $15(5.0)$ & $14(4.6)$ & $71(23.4)$ & $15(5.0)$ & $\begin{array}{l}<0.0 \\
5\end{array}$ \\
\hline Nonchewers & 0 & $11(18.6)$ & $3(5.1)$ & $5(8.4)$ & $2(3.4)$ & $4(6.8)$ & $30(50.8)$ & $4(6.8)$ & \\
\hline \multicolumn{10}{|c|}{ Tobacco smoke } \\
\hline Smokers & $1(0.5)$ & $24(12.4)$ & $51(26.4)$ & $\begin{array}{l}10 \\
(5.2)\end{array}$ & $12(6.2)$ & $14(7.3)$ & $80(41.5)$ & $1(0.5)$ & $\begin{array}{l}<0.0 \\
5\end{array}$ \\
\hline Nonsmokers & $4(2.4)$ & $30(17.8)$ & $74(43.8)$ & $\begin{array}{l}13 \\
(7.7)\end{array}$ & $5(3.0)$ & $4(2.4)$ & $21(12.4)$ & $18(10.7$ & \\
\hline \multicolumn{10}{|l|}{ Betel nut } \\
\hline Chewers & $5(1.7)$ & $54(18.4)$ & $\begin{array}{l}125 \\
(42.5)\end{array}$ & $\begin{array}{l}20 \\
(6.8)\end{array}$ & $11(3.7)$ & $7(2.4)$ & $56(19.4)$ & $16(5.4)$ & $\begin{array}{l}<0.0 \\
5\end{array}$ \\
\hline Nonchewers & 0 & 0 & 0 & $3(4.4)$ & $6(8.8)$ & $11(16.2)$ & $45(66.2)$ & $3(4.4)$ & \\
\hline
\end{tabular}

Table-3: Characteristics of patients and patients' education status $(\mathrm{N}=362)$

\begin{tabular}{|c|c|c|c|}
\hline Patients' characteristics & \multicolumn{2}{|c|}{ Education status } & $\mathbf{P}$ \\
\hline & Literate & Illiterate & \\
\hline \multicolumn{4}{|l|}{ Tobacco smokeless } \\
\hline Chewers & $105(34.7)$ & $198(65.3)$ & 0.001 \\
\hline Nonchewers & $8(13.6)$ & $51(86.4)$ & \\
\hline \multicolumn{4}{|l|}{ Tobacco smoke } \\
\hline Smokers & $62(32.1)$ & $131(67.9)$ & 0.690 \\
\hline Nonsmokers & $51(30.2)$ & $118(69.8)$ & \\
\hline \multicolumn{4}{|l|}{ Betel nut } \\
\hline Chewers & $113(38.4)$ & $181(61.6)$ & $<0.05$ \\
\hline Nonchewers & 0 & $68(100)$ & \\
\hline
\end{tabular}

Next, we investigated the relation between chewing and smoking habit and education status of the patients. We observed that out of 303 tobacco chewers, $198(65.3 \%)$ were illiterate. Further, 181 (61.6\%) patients were illiterate among betel nut chewers. Education status was statistically significant with chewing habit $(\mathrm{P}<0.05)$. Moreover, $131 \quad(67.9 \%)$ patients were identified as illiterate smokers. Smoking habit did not differ significantly with education status [Table 3]. Further, we have performed univariate analysis between education (odds ratio [OR] 3.381, 95\% confidence interval $[\mathrm{CI}] 1.547-7.389, \mathrm{P}=0.002$ ) and habit of tobacco consumption. The risk of developing HNSCC was statistically higher among illiterate tobacco chewers which were about three times more than nonchewers. Furthermore, multivariate analysis showed significant effect of education (OR $3.618,95 \%$ CI 1.643-7.970, $\mathrm{P}=0.001)$ and gender $(\mathrm{OR}$ 1.916, 95\% CI 1.032-3.554, $\mathrm{P}=0.039) \quad$ on tobacco- chewing habit. The risk of prevalence HNSCC among males was about two times higher in tobacco chewers than nonchewers. Among the illiterate tobacco chewers, there is four times higher risk of prevalence HNSCC than nonchewers [Tables 1-3].

\section{DiscussiON}

HNSCC is the most commonly diagnosed cancer worldwide. Over 100,000 cases of HNC occur each year in Bangladesh. A high incidence of smoking was reported among youth from Bangladesh, India, and Indonesia. Nearly 80,000 oral cancers are diagnosed every year in our country [19]. The true global incidence of HNSCC in young patients is unclear because most epidemiological studies do not report its incidence by age stratification. In Bangladesh, HNC accounts for $30 \%$ of all cancers [19]. The population of Bangladesh is associated with distinct demographic profile, lifestyle, food habits, and customary practices, which implicts toward higher susceptibility to develop HNSCC. HNSCC usually occurs in the sixth to seventh decades of life, but Llewellyn et al. have shown 
increased incidence of HNSCC among young [3]. Various epidemiological studies had reported a strong association with HPV in a subset of young HNSCC and nonchewers and smokers [9]. The percentage of HNSCC in younger individuals varies depending on the cutoff age chosen. In our study, we have taken the cutoff age as 39 years. According to Llewellyn et al., the incidence of HNSCC in younger individuals ranges from $0.4 \%$ to $3.6 \%$ [3], when the cutoff age was taken as $<40$ years. However, our study showed $50.8 \%$ cases in younger age group when young were defined 39 years or below. The mean age was 41 years in older age group. This significant bias may be due to habit of consuming tobacco (smokeless and smoke) and chewing betel nut at early ages in the region of Bangladesh. This is observed in our study as well. Considering the gender in the present study, males were more commonly affected than females which implicate the increased use of tobacco and betel nuts in males. This finding was similar to the study conducted by Toner and O'Regan [6]. Smoking, tobacco, and alcohol consumption are main risk factors for HNC [20]. The most common site of cancer in the present study population was oral cavity. This finding is different from the previous other studies by Gawecki et al. [21]. SCC of larynx and hypopharynx in young patients are rare and account for approximately $10 \%$ and $1 \%$ of all HNSCCs in patients aged $<40$ years [22]. In patients younger than 39 years, oral cavity was the most common site; however, hypopharynx was more common in patients older than 39 years and equal to 40 years which was different from the other studies [23]. On contrary to the findings in other studies, oral cavity and hypopharynx were the two most commonly affected sites in males, whereas in females, it was the oral cavity which was found to be more frequent in our study [24]. Tobacco both in smokeless and smoked form is known as one of the major risk factors for HNSCC. Various Bangladeshi studies had shown that tobacco smoking in the form of cigarettes, bidis, cigar/chutta/cheroot, dhunti (Goa), the water pipes/hookah Bangladesh, reverse chutta smoking has attributed to the development of HNSCC. In Bangladesh, around $57 \%$ of all men and $11 \%$ of women between 15 and 49 years of age use some form of tobacco. Uses of smokeless tobacco as well as betel quid (pan) with lime and zarda are widespread in many parts of India [25]. Tobacco consumption in India is growing at a rate of $2 \%-3 \%$ per annum [26]. A high incidence of smoking was reported among youth from Bangladesh, India, and Indonesia [27]. The high prevalence of tobacco usage has led to increase in disease burden and high health care costs in developing countries. In our study, $40.3 \%$ of the tobacco chewers had oral cancers which is similar to that observed by O'Regan et al. [28] Mafi et al. has found $81.7 \%$ of SCC in larynx with the habit of smoking; however, in our study, it was observed that $41.5 \%$ of patients had SCC of hypopharynx [23]. Among the betel nut chewers, oral cavity was the most common affected site in our study group. This finding is similar to the other studies [29]. Illiteracy was significantly associated with tobacco use in our study. This is consistent with many other studies [30]. Illiteracy and lack of awareness among the general population about the side effects of tobacco have emerged as major public health problem in Bangladesh. The limitations of our study include that the study was a retrospective one resulting in missing of data and small number of patients. Hence, further prospective studies will be of greater value in this respect. However, the strength of our study is that this is the first study from Bangladesh on young HNC patients.

\section{Conclusion}

Tobacco and betel nut consumption are the major risk factors for HNSCC. There was a positive association between tobacco use, male gender, and low education levels, and incidence of HNSCC in Dhaka City is higher than the other City. Since HNSCC cancers are highly preventable cancers, we should inform the general public, especially the younger illiterate population about the adverse health consequences of tobacco and betel nut use.

\section{Conflicts of interest}

There are no conflicts of interest.

\section{REFERENCES}

1. Jemal, A., Bray, F., Center, M. M., Ferlay, J., Ward, E., \& Forman, D. (2011). Global cancer statistics. CA: a cancer journal for clinicians, 61(2), 69-90.

2. Gupta, P. C. (1999). Mouth cancer in India: a new epidemic?. Journal of the Indian Medical Association, 97(9), 370-373.

3. Llewellyn, C. D., Johnson, N. W., \& Warnakulasuriya, K. A. A. S. (2001). Risk factors for squamous cell carcinoma of the oral cavity in young people - a comprehensive literature reviews. Oral oncology, 37(5), 401-418.

4. Schantz, S. P., \& Yu, G. P. (2002). Head and neck cancer incidence trends in young Americans, 19731997, with a special analysis for tongue cancer. Archives of Otolaryngology-Head \& Neck Surgery, 128(3), 268-274.

5. Llewellyn, C. D., Linklater, K., Bell, J., Johnson, N. W., \& Warnakulasuriya, K. A. A. S. (2003). Squamous cell carcinoma of the oral cavity in patients aged 45 years and under: a descriptive analysis of 116 cases diagnosed in the South East of England from 1990 to 1997. Oral oncology, 39(2), 106-114.

6. Toner, M., \& O’Regan, E. M. (2009). Head and neck squamous cell carcinoma in the young: a spectrum or a distinct group? Part 1. Head and neck pathology, 3(3), 246-248. 
7. Jemal, A., Siegel, R., Ward, E., Murray, T., Xu, J., \& Thun, M. J. (2007). Cancer statistics, 2007. CA: a cancer journal for clinicians, 57(1), 43-66.

8. Boyle, P., \& Levin, B. (2008). World cancer report 2008. IARC Press, International Agency for Research on Cancer.

9. Ragin, C. C. R., Modugno, F., \& Gollin, S. M. (2007). The epidemiology and risk factors of head and neck cancer: a focus on human papillomavirus. Journal of dental research, 86(2), 104-114.

10. Kreimer, A.R., Clifford, G.M., Boyle, P., Franceschi, S.(2005). Human papillomavirus types in head and neck squamous cell carcinomas worldwide: A systematic review. Cancer Epidemiol Biomarkers Prev, 14:467-75.

11. Adhikari, A., De, M. (2013). Toxic effects of betel quid. Int J Hum Genet, 13:7-14.

12. Stepanov, I., Jensen, J., Hatsukami, D., Hecht, S.S.(2008). New and traditional smokeless tobacco: Comparison of toxicant and carcinogen levels. Nicotine Tob Res, 10:1773-82.

13. Mondal, R., Ghosh, S.K. (2013). Accumulation of mutations over the complete mitochondrial genome in tobacco related oral cancer from Northeast India. Mitochondrial DNA, 24:432-9.

14. Schantz, S.P., Hsu, T.C., Ainslie, N., Moser, R.P.(1989). Young adults with head and neck cancer express increased susceptibility to mutagen induced chromosome damage. JAMA, 262:3313-5.

15. Sturgis, E.M., Wei, Q. (2002). Genetic susceptibility - Molecular epidemiology of head and neck cancer. Curr Opin Oncol, 14:310-7.

16. Llewellyn, C.D., Johnson, N.W., Warnakulasuriya, K.A. (2004). Risk factors for oral cancer in newly diagnosed patients aged 45 years and younger: A case control study in Southern England. J Oral Pathol Med. 33:525-32.

17. Sturgis, E.M., Wei, Q., Spitz, M.R. (2004). Descriptive epidemiology and risk factors for head and neck cancer. Semin Oncol. 31:726-33.

18. Dahlstrom, K.R., Little, J.A., Zafereo, M.E., Lung, M., Wei, Q., Sturgis, E.M. (2008). Squamous cell carcinoma of the head and neck in never smoker never drinkers: A descriptive epidemiologic study. Head Neck, 30:75-84.

19. Kulkarni, M.K. (2013). Head and neck cancer burden in India. Int J Head Neck Surg. 4:29-35.
20. Parkin, D.M., Bray, F., Ferlay, J., Pisani, P.(2005). Global cancer statistics, 2002. CA Cancer J Clin. 55:74-108.

21. Gawecki, W., Szyfter, K., Szyfter, W. (2007). Clinical and histopathological analysis of squamous cell carcinoma of the head and neck in young adults. Otolaryngol Pol. 61:11-6.

22. Patel, S.C., Carpenter, W.R., Tyree, S., Couch, M.E., Weissler, M., Hackman, T. (2011). Increasing incidence of oral tongue squamous cell carcinoma in young white women, age 18 to 44 years. J Clin Oncol. 29:1488-94.

23. Mafi, N., Kadivar, M., Hosseini, N., Ahmadi, S., Zare-Mirzaie, A. (2012). Head and neck squamous cell carcinoma in Iranian patients and risk factors in young adults: A fifteen year study. Asian Pac J Cancer Prev, 13:3373-8.

24. Müller, S., Pan, Y., Li, R., Chi, A.C.(2008). Changing trends in oral squamous cell carcinoma with particular reference to young patients: 19712006. The Emory University experience. Head Neck Pathol, 2:60-6.

25. Kekatpure, V., Kuriakose, M.A. (2010). Oral Cancer in India: Learning From Different Populations. National Newsletter and Website from New York Presbyterian Hospital. 14. Available from:

http://www.nypcancerprevention.com/issue/14/can cer_ prevention/feature/india.shtml. [Last accessed on 2017 Dec 15].

26. Jandoo, T., Mehrotra, R. (2008).Tobacco control in India: Present scenario and challenges ahead. Asian Pac J Cancer Prev. 9:805-10.

27. Jha, P., Chaloupka, F.J.(1999). Curbing the Epidemic: Governments and Economics of Tobacco Control. Washington, DC: World Bank.

28. O'Regan, E.M., Timon, C., Sheils, O., Codd, M., O'Leary, J.J., Toner, M. (2006). Squamous cell carcinoma of the head and neck in young Irish adults. Br J Oral Maxillofac Surg; 44:203-6.

29. Merchant, A., Husain, S.S., Hosain, M., Fikree, F.F., Pitiphat, W., Siddiqui, A.R. (2000). Paan without tobacco: An independent risk factor for oral cancer. Int J Cancer, 86:128-31.

30. Gupta, R. (2006). Smoking, educational status and health inequity in India. Indian J Med Res. 124:1522.

31. Hussain, S.M. (2013). Comprehensive update on cancer scenario of Bangladesh. South Asian J Cancer, 2(4):279-84. 